\title{
Universal health coverage still rare in Africa
}

$\mathrm{S}$ ix years after the World Health Assembly urged African nations to abandon health care user fees, which were driving people into poverty, in favour of some manner of national health insurance schemes, only two nations are providing universal coverage for at least a majority of their residents.

In cases where health insurance plans have been introduced, premiums are proving to be as prohibitory as were user fees. There've been problems collecting them in some nations and premium-based models, for the most part, haven't generated the financial resources needed to sustain health care systems, experts say.

Several African nations are slowly "moving in the direction" of universal health coverage and national health insurance plans, says Dr. James Akazili, a health economist and principal research officer with Navrongo Health Research Centre in Ghana.

But many African governments lack the political will to introduce plans, or the ability to design plans with innovative funding mechanisms to pay for them, says Kwesi Eghan, a senior program associate for Management Sciences for Health, a nonprofit international health organization based in Cambridge, Massachusetts.

Only Rwanda and Ghana appear to have made significant progress toward providing universal health coverage through a national health insurance scheme for the majority of their citizens. And in countries which have some manner of non-national health insurance scheme - whether community-, private- or employer-based their reach is typically very limited.

"Many African countries, including Nigeria, Tanzania, Kenya, Uganda, and Cameroon have community-based health insurance schemes that offer protection for the poor but are unsustainable because poor people can't contribute enough premiums to maintain the schemes," says John Ataguba, a researcher/lecturer with the Health Economics Unit of the School of Public

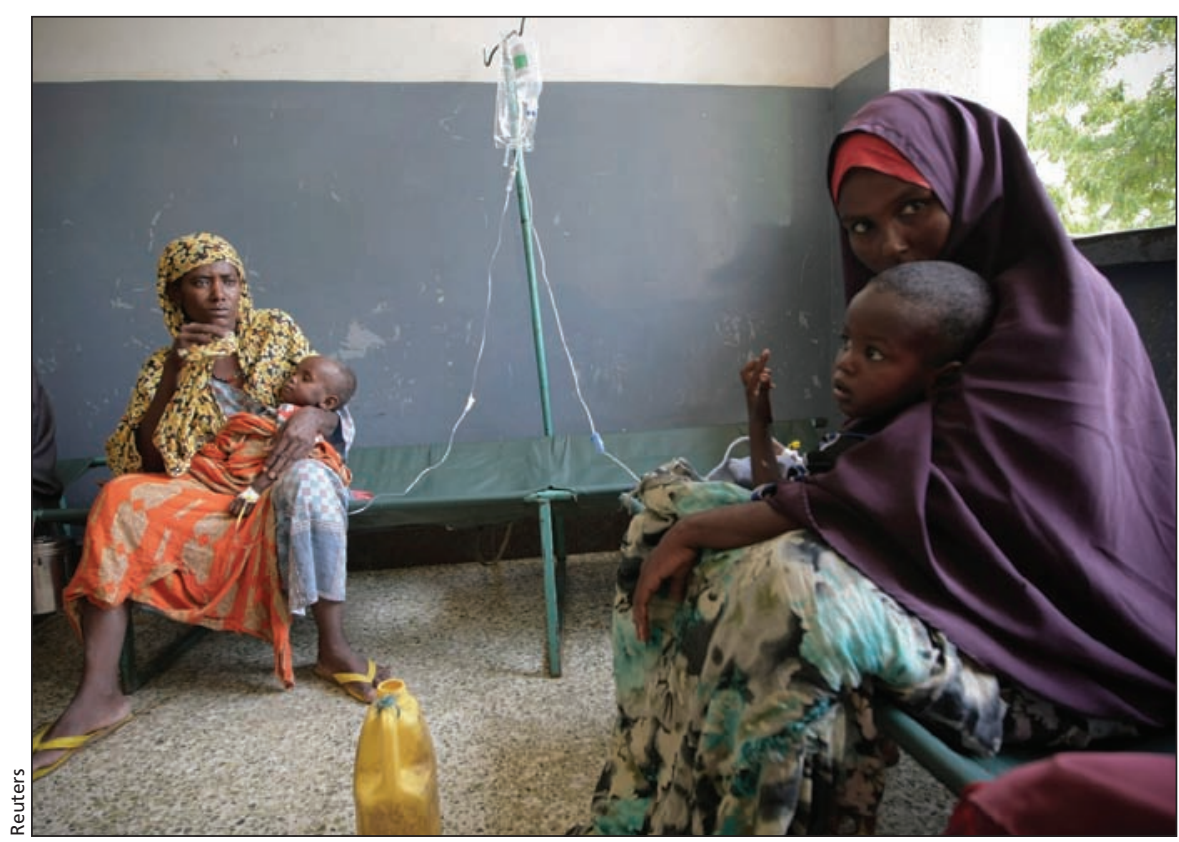

Children share an intravenous drip at Banadir Hospital in Mogadishu, Somalia.

Health and Family Medicine at the University of Cape Town, South Africa.

South Africa is typical in that it currently has private health insurance plans which cover about $16 \%$ of the population but are out of the financial reach of most people, Ataguba adds. But in April 2012, the South African government will take the tentative steps toward the creation of a national health insurance system by providing conditional grants to five-year pilot projects aimed at determining "how the service benefits will be designed, how the population will be covered and how the services will be delivered" (www.doh.gov .za/list.php?type $=$ National $\% 20$ Health $\% 20$ Insurance).

Several countries continue to seek universal health coverage funded through user fees, while exempting vulnerable population groups within society. In Mali and Burkina Faso, for example, there are no user fees for children under the age of five or for pregnant women.

In other nations, such as Nigeria, Tanzania, and Kenya, health insurance schemes have been introduced but only for public sector workers, who pay monthly premiums. Nongovernment workers in those nations typically do not have, or cannot afford, health insurance except, of course, for the very wealthy in the private sector.

"In West Africa, formal sector [government] employees constitute only about $10 \%-15 \%$ of the population, so [the] majority of people in the informal sector would have to pay premiums but it is difficult to collect premiums from the informal sector workers because they don't earn fixed incomes," says Dr. Valery Ridde, assistant professor with the Department of Social and Preventive Medicine at the centre de recherche du Centre Hospitalier de l'Université de Montréal in Quebec.

Rwanda and Ghana have progressed the furthest toward some manner of universal health coverage.

Rwanda has long been lauded for providing comprehensive health insurance but its system was largely funded through foreign aid. But the government recently indicated that it would be retooling the system so that it would be community-based and reliant on premiums that are directly based upon 
a citizen's ability to pay. The changes include a threefold increase in the minimum premium for the lowest tier of coverage, which some believe will be untenable for many of the country's poor. Premiums under the new scheme will range from RWF3000 to RWF7000 (about \$5 to \$12) per person. Previously, those on the health insurance system's lowest tier paid a flat rate of RWF1000 (under \$2) per person, with many of the poorest Rwandans unable to pay even that amount (www.cmaj.ca/lookup/doi /10.1503/cmaj.109-3956).

The Ghanaian government introduced a national health insurance scheme in 2005 that is financed from monthly deductions of 2.5 percentage points of government worker's contribution to the social security fund, a direct premium of between US\$4.80 and US\$32 per year for nongovernmental workers and a $2.5 \%$ national health insurance levy on goods and services.

"We have innovative ways of covering the poor and the vulnerable and a comprehensive premium exemption policy," for children, pregnant women, the elderly and the indigent, says Dr. Nicholas A. Tweneboa, director of operations for Ghana's National Health Insurance Authority. As of December 2010 , nearly $75 \%$ of the country's roughly 24 million people were registered with the scheme and about $70 \%$ of enrollees are exempted from paying premiums.

Premiums for nongovernment workers "were supposed to be based on income levels, but currently each district charges a flat premium because of the difficulty of grouping people in various income levels for the different premiums," he says, adding that identifying the poor is a challenge "because some religious people don't want to be labelled as poor." - Bernard Appiah, College Station, Tex.

CMAJ 2012. DOI:10.1503/cmaj.109-4052 